\title{
Temporal and spatial variations in the magnitude of completeness for homogenized moment magnitude catalogue for northeast India
}

\author{
RANJit DAS, H R WASON* and M L Sharma \\ Department of Earthquake Engineering, Indian Institute of Technology Roorkee, Roorkee, India. \\ Corresponding author.e-mail: Wason2009@gmail.com
}

\begin{abstract}
Northeast India region is one of the most seismically active areas in the world. Events data for the period 1897-2010, used in this study has been largely compiled from global ISC, NEIC and GCMT databases. Historical seismicity catalogue of Gupta et al (1986) and some events data from the bulletins of India Meteorological Department are also used. Orthogonal regression relations for conversion of body and surface wave magnitudes to $M_{\mathrm{w}, \mathrm{HRVD}}$ based on events data for the period 1978-2006 have been derived. An Orthogonal Standard Regression (OSR) relationship has also been obtained for scaling of intensity estimates to $M_{\mathrm{w}, \text { NEIC }}$ using 126 global intensity events with intensity VI or greater during the period 1975-2010.

Magnitude of completeness and Gutenberg-Richter (GR) recurrence parameter values have been determined for the declustered homogenized catalogue pertaining to four different time periods namely, 18971963, 1964-1990, 1964-2000 and 1964-2010. The $M_{\mathrm{c}}$ and ' $b$ ' values are observed to decrease and increase, respectively, with addition of newer data with time. The study region has been subdivided into nine seismogenic zones keeping in view the spatial variations in earthquake occurrence and prevalent tectonics. $M_{c}, ' b$ ' and ' $a$ ' values have been estimated with respect to each zone, and the variations in the values of these parameters have been analysed.
\end{abstract}

\section{Introduction}

The northeast (NE) India region, encompassed within the geographical coordinates $20^{\circ}-30^{\circ} \mathrm{N}$ latitude and $87^{\circ}-98^{\circ} \mathrm{E}$ longitude, is one of the most seismically prone regions in the world. Two great earthquakes, the Shillong earthquake of 12 June 1897 and the Assam earthquake of 15 August 1950, both with magnitude greater than 8.0, have occurred in this region in the recent past. The frequency of moderate to large magnitude earthquakes occurrence is also significantly higher in this region.
Earthquake magnitude is one of the most widely used and accepted descriptor of the size of an earthquake. However, magnitude determinations for different earthquake occurrences in space and time generally lack consistency due to the inherent complex nature of the earthquake phenomena as well as the differences in instrument characteristics and station coverage used for recording of seismic waves at different epicentral distances. The scaling relationships between different magnitude scales are, therefore, of paramount importance for the purpose of homogenization of seismicity catalogues. Earthquake catalogues showing the seismicity for the NE

Keywords. Northeast India region; orthogonal standard regression; magnitude of completeness; seismogenic zones. 
India region from historical times to around 1964, when the intensive deployment of high quality instrumentation was started in the region, are heterogeneous in earthquake magnitude estimates (e.g., Bapat et al 1983; Gupta et al 1986; Chandra 1992).

The magnitude of completeness $\left(M_{\mathrm{c}}\right)$ of a seismic catalogue, also called as 'threshold' or 'cutoff' magnitude, defined as the lowest magnitude at which $100 \%$ of the events in a space-time volume are detected (Woessner and Wiemer 2005), is of basic importance for the studies related to seismicity and seismic hazard assessment. $M_{\mathrm{c}}$ value also influences the estimation of GR magnitudefrequency recurrence parameters. The magnitude of completeness may also change with time and space for most of the catalogues and, in general, its value is reduced with improvement in the detection capability and/or in the method of data analysis.

Most of the available scaling relationships between different magnitude types for the study region have been derived based on the Standard Linear Regression (SR) method assuming one of the magnitudes to be error free. The use of SR procedure may be inappropriate if both the magnitudes have measurement errors due to saturation or otherwise. In such a situation, it is better to use Orthogonal Standard Regression (OSR) procedure which takes into account the errors on both the magnitudes (Stromeyer et al 2004; Castellaro et al 2006; Joshi and Sharma 2008; Thingbaijam et al 2008; Ristau 2009). However, the use of this regression procedure requires the knowledge of the error variance ratio $(\eta)$ for the two magnitudes, which is usually not known. In the absence of actual error variance estimates, the error variances of the two magnitudes are assumed to be equal. Thus, the error variance ratio can be taken as equal to unity (Ambraseys 1990; Gusev 1991; Panza et al 1993; Cavallini and Rebez 1996; Kaverina et al 1996; Gutdeutsch et al 2002; Stromeyer et al 2004). Qualitatively, it is suggested that the magnitude scaling relationships should be based on the OSR procedure when square root of the error variance ratio lies between 0.7 and 1.8 (Castellaro and Bormann 2007).

In the present study, OSR relationships have been derived for conversion of $m_{\mathrm{b}}$ and $M_{\mathrm{s}}$ magnitudes into the unified moment magnitude, $M_{\mathrm{w}, \mathrm{HRVD}}$, based on events data for the period 1978-2006. A scaling relation between MMI intensity estimates and $M_{\mathrm{w}, \text { NEIC }}$ is also obtained using 126 global events for the period 1975-2010. The OSR relationships derived in this study have been compared with the corresponding OSR relationships for NE India and its adjoining region as reported by Das et al (2011a).

Declustering of the homogenized catalogue for NE India obtained by using the intensity scaling relationship developed in this study and magnitude conversion relations given by Das et al (2011a), has been performed using the method of Uhrhammer (1986) for the catalogue period 1897-2010. Magnitude of completeness and its uncertainty have been determined for four catalogue periods namely, 1897-1963, 1964-1990, 1964-2000 and 1964-2010, using the Entire Magnitude Range (EMR) method (Woessner and Wiemer 2005). The $M_{\mathrm{c}}$ value is observed to have decreased with increase in the instrumentally recorded data. The study region has been subdivided into nine seismogenic zones keeping in view, the spatial variations in earthquake occurrence and prevalent tectonics. $M_{c}$, $b$ ', and ' $a$ ' values have been estimated with respect to each zone. The variations in the values of these parameters in space and time are analysed.

\section{Seismicity of NE India}

A seismotectonic map showing the epicenters of $M_{\mathrm{w}} \geq 2$ events for the period 1987-2010 and the tectonic features of NE India region, lying between $20^{\circ}-30^{\circ} \mathrm{N}$ latitude and $87^{\circ}-98^{\circ} \mathrm{E}$ longitude is shown in figure 1. The Shillong earthquake of 12 June $1897\left(M_{\mathrm{w}}=8.7\right)$ and the Assam earthquake of 15 August $1950\left(M_{\mathrm{w}}=8.1\right)$ are two of the largest earthquakes in the world which occurred in this region in the recent past. Further, this region has also experienced several large earthquakes $(M \geq$ 7.0), causing loss of human lives and destruction to buildings.

Dutta (1964) subdivided this region into four main seismogenic source zones: the Eastern Syntaxis (zone I), the Arakan-Yoma Subduction Belt (zone II), the Shillong Plateau (zone III), and Main Central Thrust (MCT) and Main Boundary Thrust (MBT) of the Himalayan Frontal Thrusts (zone IV). The seismicity in this region is related to the collision of the Indian Plate with Tibet towards the north and the Burmese landmass towards the east. Such collisions resulted in the formation of the Himalaya Thrust system in the north, ArakanYoma Mountain Arc, Naga Hills and Tripura Folded Belt in the east and also caused the uplift of the Shillong Plateau. The eastern Himalaya and the Arakan-Yoma Mountain Arc meet and define the Assam Syntaxis encasing between them the Upper Assam Petroliferous Tertiary Basin. The Shillong massif stands out as a plateau with an average elevation of $1500 \mathrm{~m}$ at the SW mouth of this basin.

The four main zones given by Dutta (1964) have been further subdivided into nine seismogenic zones as given in table 1 and shown in figure 2. This subdivision is based on tectonic and geological similarities, focal mechanism solutions (Angelier and 


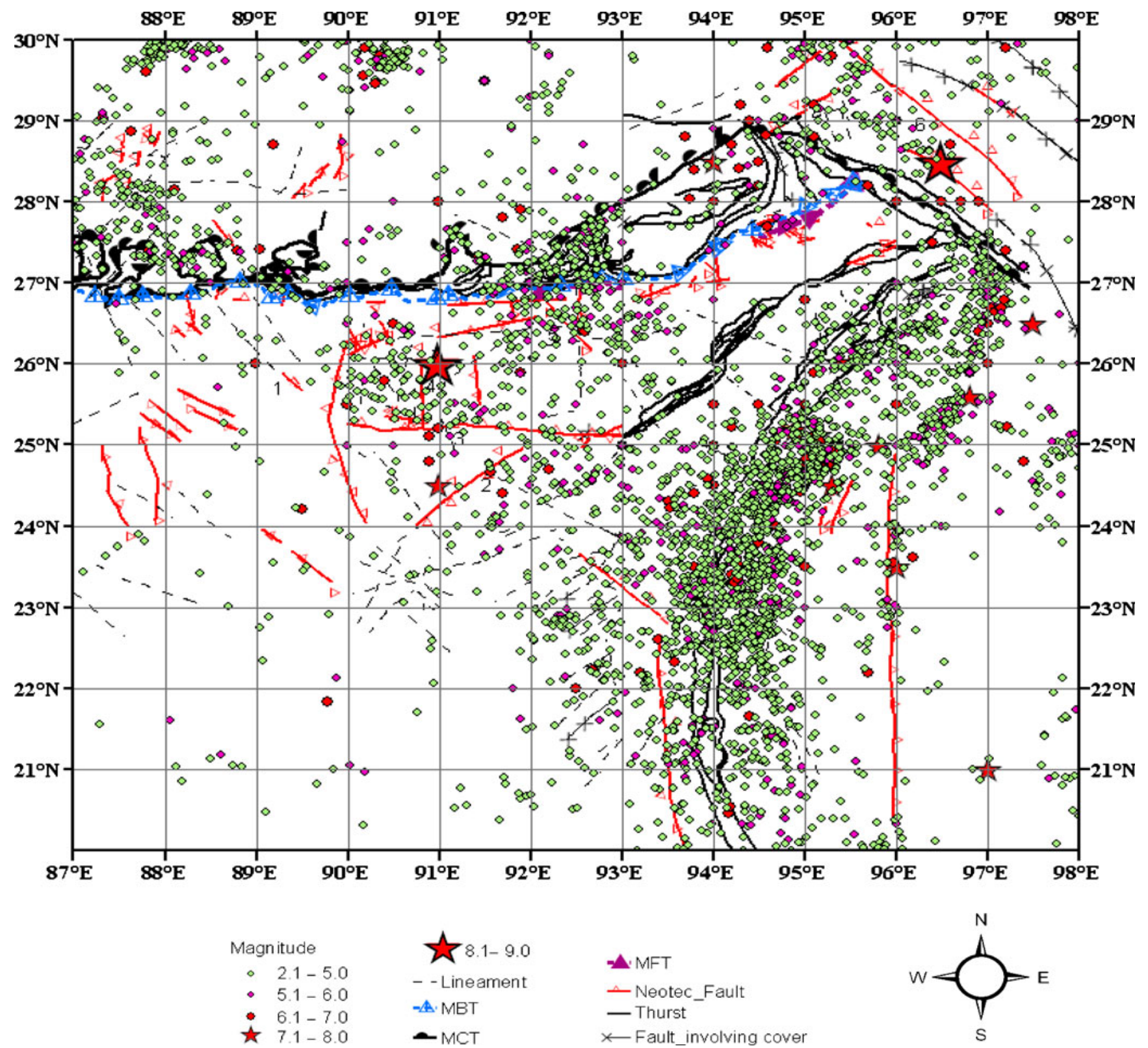

Figure 1. Seismotectonic map showing the epicentres and the tectonic features of NE India region on GIS platform depicting seismicity for $M_{\mathrm{w}} \geq 2.0$.

Table 1. Different seismogenic zones for NE India region.

\begin{tabular}{lll}
\hline $\begin{array}{l}\text { Seismogenic } \\
\text { zone }\end{array}$ & \multicolumn{1}{c}{ Major division } & \multicolumn{1}{c}{ Subdivision } \\
\hline I & Indo Burma Fault Belt & North-south Indo-Burma Fold Belt \\
II & Indo Burma Fault Belt & NE-SW Indo-Burma Fold Belt \\
III & Plateau region & Sagging Fault region \\
IV & Mishmi Massif & NW-SE trending feature \\
V & Plateau region & Tibetan Plateau \\
VI & Himalayan Mountain Belt & Eastern MCT \\
VII & Shillong Massif & Shillong Plateau \\
VIII & Bengal Basin & Sylhet Fault \\
IX & Himalayan Mountain Belt & NE-SW trending structure \\
\hline
\end{tabular}




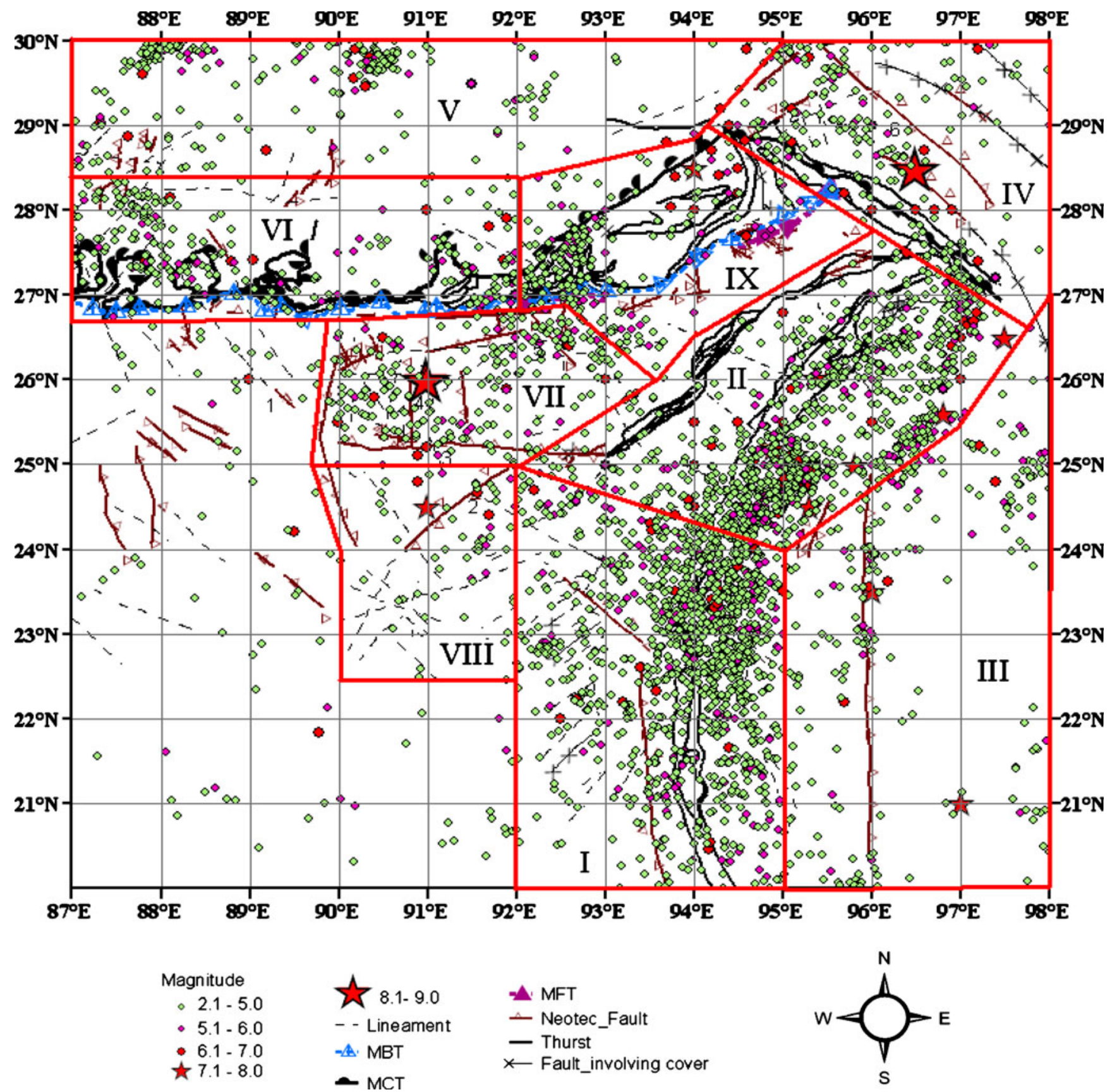

Figure 2. Seismogenic source zones (I-IX) considered for NE India region.

Baruah 2009) and spatial distribution of earthquake events.

\section{Data}

In this study, 3711 earthquake events data for the period 1897 to 2010 has been compiled from various databases. For the historical seismicity during 1897 to 1962 , event data is taken from the catalogue by Gupta et al (1986). For the period 1964 to 2010 , event data has been compiled from global ISC, NEIC databases. Data for the year 1963 has been adopted from the International Seismological
Summary (ISS). Moment magnitudes data of GCMT and NEIC have been considered for the periods 1978-2006 and 1975-2010. Some events for the period 1999-2006 are also considered from seismological bulletins of the India Meteorological Department.

\section{Magnitude conversions}

OSR is used to develop relationship between two variables when measurement errors are considered in both the variables. The procedure for carrying 
out the OSR is described by Madansky (1959), Fuller (1987), Kendall and Stuart (1979), Carroll and Ruppert (1996), and Das et al (2011b), and thus is not included here.

\subsection{Surface wave and body wave conversion}

The OSR procedure has been used for conversion of $M_{\mathrm{s}}$ and $m_{\mathrm{b}}$ magnitudes to $M_{\mathrm{w}, \mathrm{HRVD}}$. The OSR relationship for $M_{\mathrm{s}, \text { ISC }}$ to $M_{\mathrm{w}, \mathrm{HRVD}}$ conversion in the range $4.1 \leq M_{\mathrm{s}, \mathrm{ISC}} \leq 6.9$, based on 98 events data and considering $\eta=1$, is obtained as given below.

$$
\begin{aligned}
M_{\mathrm{w}, \mathrm{HRVD}}= & 0.637( \pm 0.001) M_{\mathrm{s}, \mathrm{ISC}} \\
& +2.213( \pm 0.299) .
\end{aligned}
$$
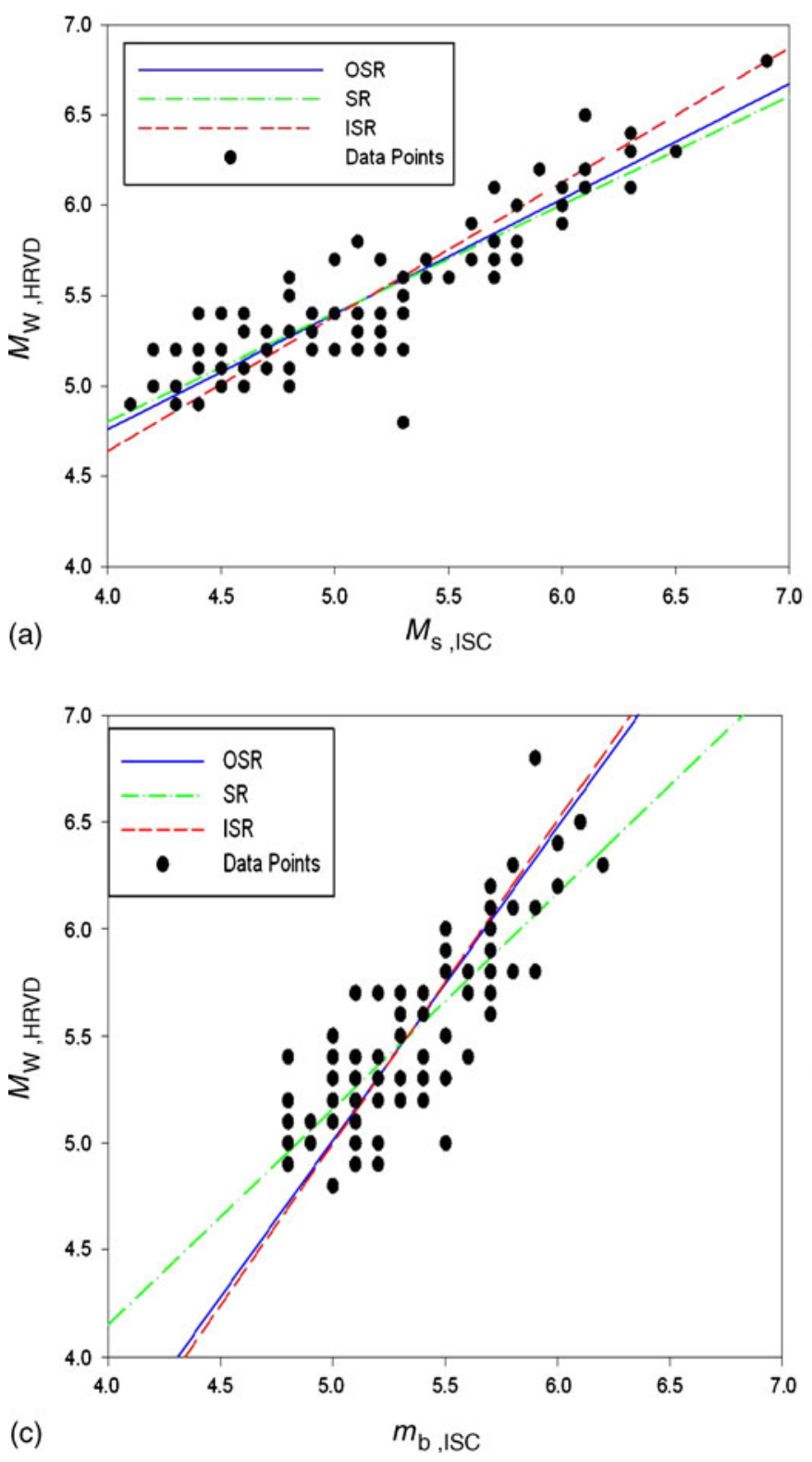

Similarly, for conversion of $M_{\mathrm{s}, \text { NEIC }}$ to $M_{\mathrm{w}, \mathrm{HRVD}}$, we consider 59 events in the range $4.8 \leq M_{\mathrm{s}, \text { NEIC }} \leq$ 6.2 , and the OSR relationship is as follows.

$$
\begin{aligned}
M_{\mathrm{w}, \mathrm{HRVD}}= & 0.732( \pm 0.001) M_{\mathrm{s}, \mathrm{NEIC}} \\
& +1.711( \pm 0.037) .
\end{aligned}
$$

The plots of the above relationships are shown in figure $3(\mathrm{a}$ and $\mathrm{b})$.

For conversion of $m_{\mathrm{b}, \text { ISC }}$ to $M_{\mathrm{w}, \mathrm{HRVD}}$ for the magnitude range $4.8 \leq m_{\mathrm{b}, \mathrm{ISC}} \leq 6.2$, and $m_{\mathrm{b}, \mathrm{NEIC}}$ to $M_{\mathrm{w}, \mathrm{HRVD}}$ in the range $4.8 \leq m_{\mathrm{b}, \text { NEIC }} \leq 6.8$, we follow the same approach using datasets of 98 and 116 events, respectively, for the period 1978-2006. The OSR relationships obtained using $\eta=0.2$,
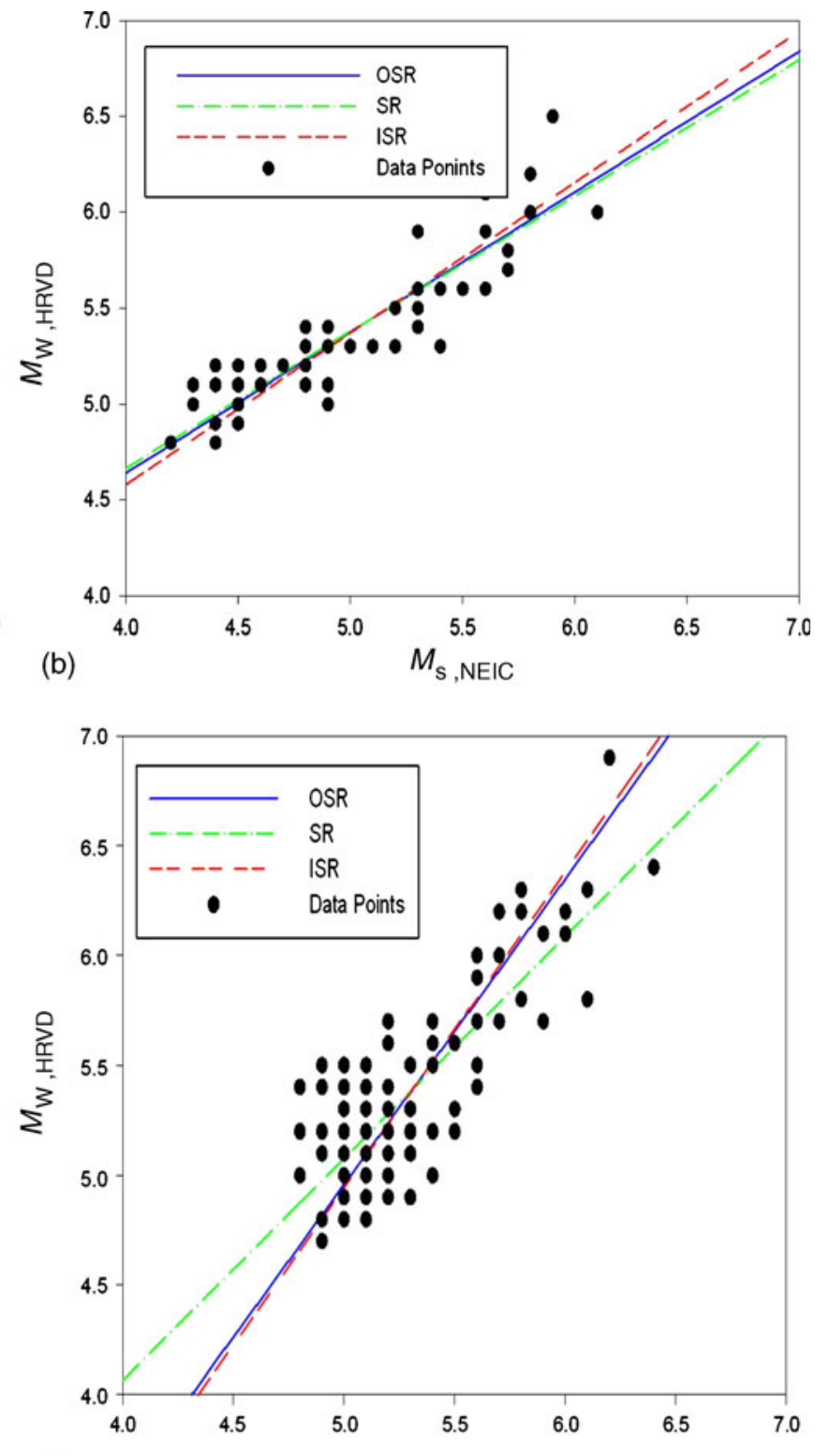

(d)

Figure 3. Plots of regression relationships (OSR, SR, ISR) for different magnitude conversions; (a) $M_{\mathrm{S}, \text { ISC }} \mid M_{\mathrm{w}, \mathrm{HRVD}}$ relationship; (b) $M_{\mathrm{s}, \text { NEIC }} \mid M_{\mathrm{w}, \text { HRVD }}$ relationship; (c) $m_{\mathrm{b}, \text { ISC }} \mid M_{\mathrm{w}, \text { HRVD }}$ relationship, and (d) $m_{\mathrm{b}, \text { NEIC }} \mid M_{\mathrm{w}, \text { HRVD }}$ relationship. 


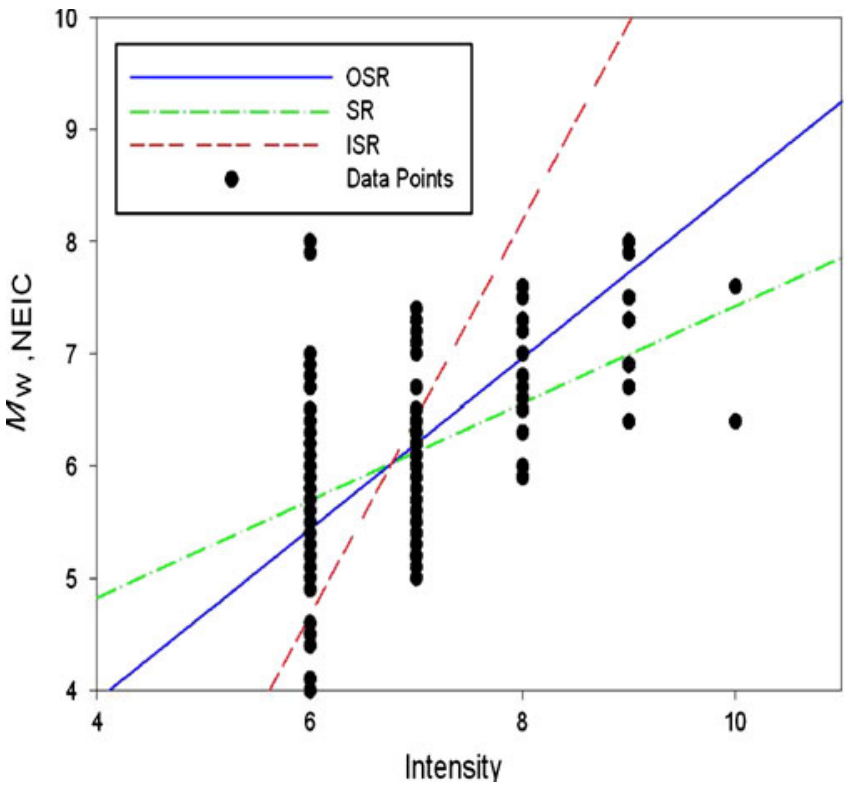

Figure 4. Plot of OSR relationship for scaling of intensity

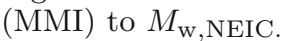

are given below and the plots are shown in figure $3(\mathrm{c}$ and $\mathrm{d})$.

$$
\begin{aligned}
& M_{\mathrm{w}, \mathrm{HRVD}}=1.46( \pm 0.011) m_{\mathrm{b}, \mathrm{ISC}}-2.31( \pm 0.34) . \\
& M_{\mathrm{w}, \mathrm{HRVD}}=1.39( \pm 0.007) m_{\mathrm{b}, \mathrm{NEIC}} \\
&-1.99( \pm 0.2) .
\end{aligned}
$$

The OSR conversion relationships derived above for the NE India region have been compared with the corresponding OSR relationships by Das et al (2011a) for NE India and its adjoining region. It is observed that the regression relations derived in this paper for NE India region are almost similar to those given by Das et al (2011a), but have slightly higher uncertainties in the regression parameters. Therefore, for homogenization of the catalogue, the OSR conversion relationships given by Das et al (2011a) have been used, which are reproduced below for easy reference.

$$
\begin{aligned}
M_{\mathrm{w}, \mathrm{HRVD}}= & 0.6389( \pm 0.0006) M_{\mathrm{s}, \mathrm{ISC}}+2.20( \pm 0.016), \\
& 4.1 \leq M_{\mathrm{s}, \mathrm{ISC}} \leq 6.9
\end{aligned}
$$
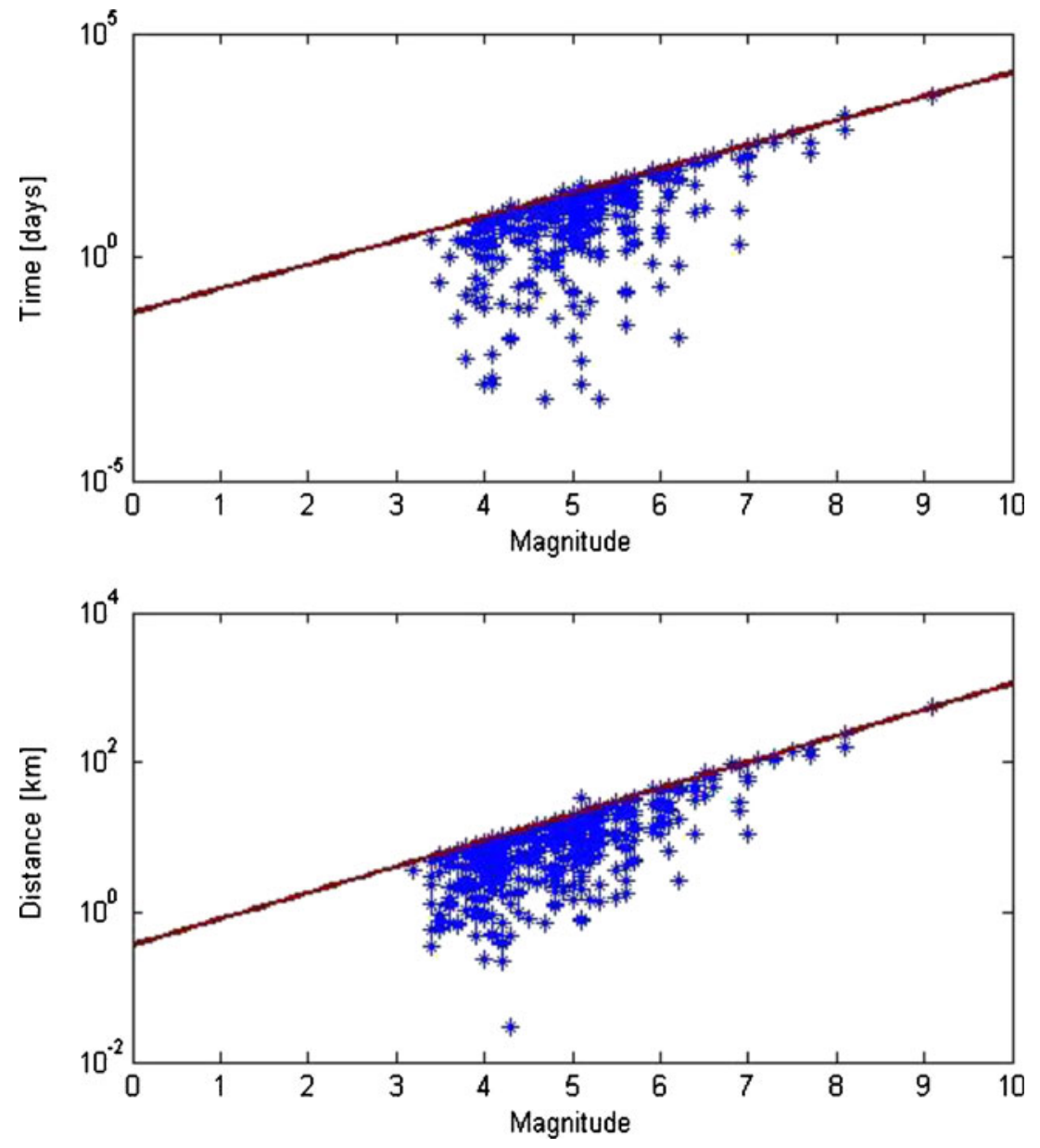

Figure 5. Magnitude dependent space and time windows used for removal of aftershocks (dependents events). The asterisks below the window lines are taken to be dependent events. 
$M_{\mathrm{w}, \mathrm{HRVD}}=0.66( \pm 0.0007) M_{\mathrm{s}, \mathrm{NEIC}}+2.13( \pm 0.0201)$, $4.4 \leq M_{\mathrm{s}, \mathrm{NEIC}} \leq 6.3$

$M_{\mathrm{w}, \mathrm{HRVD}}=1.40( \pm 0.0043) m_{\mathrm{b}, \mathrm{ISC}}-1.98( \pm 0.122)$, $4.7 \leq m_{\mathrm{b}, \mathrm{ISC}} \leq 6.6$

$M_{\mathrm{w}, \mathrm{HRVD}}=1.37( \pm 0.006) m_{\mathrm{b}, \mathrm{ISC}}-1.77( \pm 0.157)$, $4.6 \leq m_{\mathrm{b}, \mathrm{NEIC}} \leq 6.8$

\subsection{Intensity conversion relation}

The intensity data for the study region is found to be very scarce. Therefore, we use 126 intensity
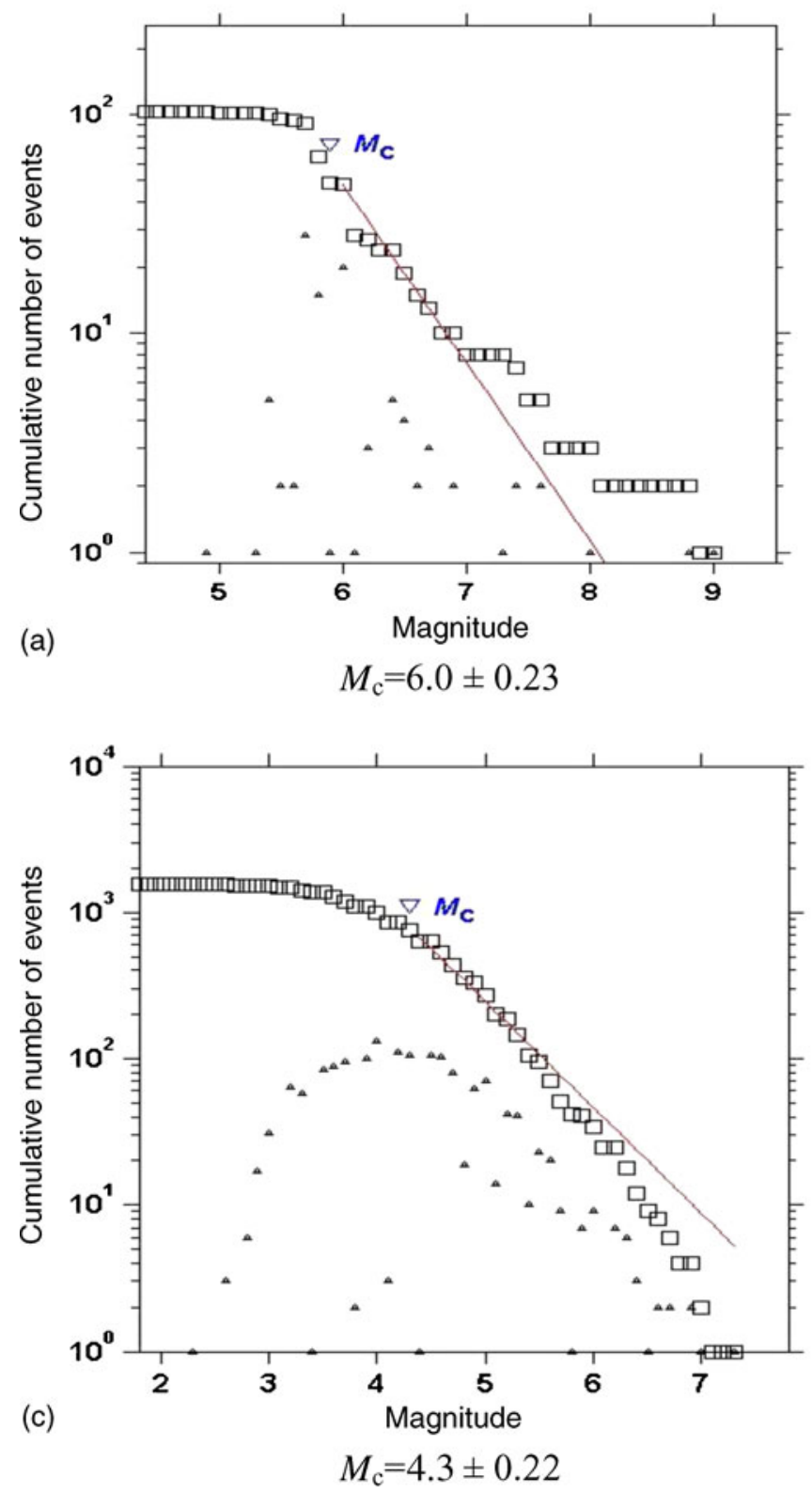

events data with MMI intensity $\left(I_{\max }\right)$ greater than or equal to VI for the entire globe for which $M_{\mathrm{w}, \text { NEIC }}$ values are available. An OSR relationship obtained is given as below.

$$
\begin{aligned}
M_{\mathrm{w}, \mathrm{NEIC}}= & 0.762( \pm 0.001) I_{\max } \\
& +0.865( \pm 0.014) .
\end{aligned}
$$

The plot of the above relation is shown in figure 4 .

\section{Declustering of the catalogue}

An earthquake sequence normally consists of foreshocks-mainshock-aftershocks. The foreshocks
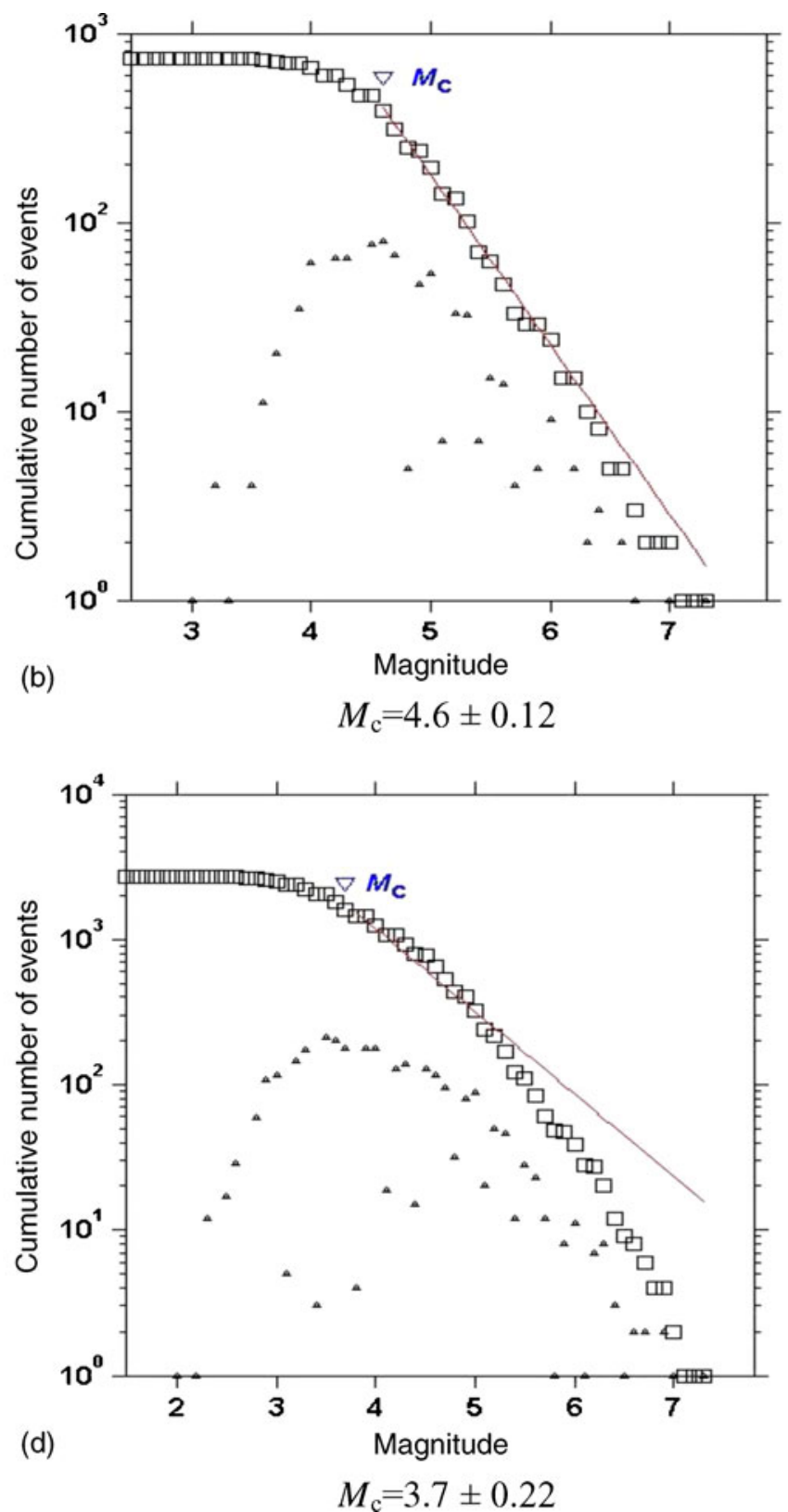

Figure 6. Plots of cumulative number of events with magnitude higher than the corresponding magnitude for different catalogue periods (a) 1897-1963, (b) 1964-1990, (c) 1964-2000, and (d) 1964-2010, along with $M_{\mathrm{c}}$ values given by EMR method. 
and aftershocks being dependent events should be eliminated from the catalogue for the estimation of seismic hazards. Several methods have been proposed for declustering a catalogue (e.g., Utsu 1965; Gardner and Knopoff 1974; Reasenberg 1985; Uhrhammer 1986). We follow the method of Uhrhammer (1986) for declustering the catalogue using a moving space and time window approach (figure 5). On declustering, we find a total of 905 $(24.387 \%)$ events removed from the catalogue for the period 1897-2010, homogenized by the OSR procedure.

\section{Determination of magnitude of completeness by the entire magnitude range method}

In order to find the temporal variations in earthquake occurrences in the NE India region, declustered earthquake catalogues for the periods 18971963, 1964-1990, 1964-2000 and 1964-2010 have been analysed. Graphs between different magnitudes and the corresponding cumulative number of earthquakes with magnitude greater than the corresponding magnitudes have been plotted (figure $6 \mathrm{a}-\mathrm{d}$ ). Estimates of $M_{\mathrm{c}}$ and its uncertainty $\partial M_{\mathrm{c}}$ have been determined by the EMR method (Wiemer 2001) for different catalogue periods using ZMAP software. The $M_{\mathrm{c}}$ values are observed to decrease with addition of newer data with time (table 2). As the detection threshold for the study region improved from 1964 onwards leading to recording of larger number of smaller magnitude earthquakes in proportion to large magnitude events, ' $b$ ' value has been found to steadily increase with time as shown in table 2 .

Further, magnitude of completeness $M_{\mathrm{c}}$, ' $b$ ' and ' $a$ ' values have also been estimated for the nine seismogenic zones into which the study region has been subdivided. For determination of $M_{\mathrm{c}}$ values for different seismic zones, events data for the period 1964-2010 only has been used, whereas the entire catalogue for the period 1897-2010, has been considered for the estimation of ' $b$ ' and ' $a$ ' values. The values obtained for different seismogenic zones are given in table 3 .

Table 2. Estimation of $M_{\mathrm{c}}$, ' $b$ ' and ' $a$ ' values for different catalogue periods.

\begin{tabular}{lccc}
\hline $\begin{array}{l}\text { Catalogue } \\
\text { period }\end{array}$ & $M_{\mathrm{c}}$ & $b$ & $a$ \\
\hline $1897-1963$ & $6.0 \pm 0.23$ & 0.48 & 4.52 \\
$1964-1990$ & $4.6 \pm 0.12$ & 0.89 & 6.66 \\
$1964-2000$ & $4.3 \pm 0.22$ & 0.94 & 7.12 \\
$1964-2010$ & $3.7 \pm 0.22$ & 0.99 & 7.46 \\
\hline
\end{tabular}

Table 3. Estimation of $M_{\mathrm{c}}$, ' $b$ ' and ' $a$ ' values for different seismogenic zones.

\begin{tabular}{lccc}
\hline Seismogenic & & & \\
zone & $M_{\mathrm{c}}$ & $b$ & $a$ \\
\hline I & 3.9 & 0.88 & 6.47 \\
II & 3.9 & 0.78 & 6.15 \\
III & 4.1 & 0.63 & 5.28 \\
IV & 4.0 & 0.65 & 5.24 \\
V & 3.8 & 0.73 & 5.21 \\
VI & 3.8 & 0.77 & 5.28 \\
VII & 3.9 & 0.5 & 4.04 \\
VIII & 3.7 & 0.54 & 3.78 \\
IX & 4.3 & 0.71 & 5.16 \\
\hline
\end{tabular}

Seismogenic zones, VI and IX showing the compressional tectonics in NS direction have almost similar ' $b$ ' values. Seismogenic zones I and II having largely EW trends and deeper events depict relatively higher ' $b$ ' values of 0.88 and 0.78 , respectively. Seismogenic zones, VII and VIII, with seismicity more similar to characteristic earthquakes are found to have low $b$ values of 0.5 and 0.54 , respectively. Several geologists have reported about the abrupt cut-off of MCT by Mishmi Thrust and, therefore, the characteristics of the seismogenic zone IV with $0.65^{\prime}$ ' $b$ ' value are different from neighbouring zones.

The maximum $M_{\mathrm{c}}$ value obtained is 4.3 for the seismogenic zone IX and the minimum value of $M_{\mathrm{c}}$ is 3.7 for zone VIII. From table 3, it is revealed that the $M_{\mathrm{c}}$ value valid for the entire NE India region can be considered to be 4.3 for the catalogue period 1964-2010.

\section{Discussion and conclusions}

In this study, earthquake magnitude data in respect of 3711 events pertaining to the NE India region during the time period 1897-2010 has been compiled. Four catalogue periods namely, 18971963, 1964-1990, 1964-2000 and 1964-2010 have been considered.

As the seismic catalogues are heterogeneous in magnitude types, OSR relationships have been derived for conversion of $m_{\mathrm{b}}$ and $M_{\mathrm{s}}$ magnitudes to $M_{\mathrm{w}, \mathrm{HVRD}}$. Surface wave magnitude conversion relationships have been derived for the ranges $4.1 \leq$ $M_{\mathrm{s}, \mathrm{ISC}} \leq 6.9$ and $4.8 \leq M_{\mathrm{s}, \mathrm{NEIC}} \leq 6.2$, based on 98 and 59 events data for the period 1978-2006, respectively. The $m_{\mathrm{b}, \mathrm{ISC}}$ to $M_{\mathrm{w}, \mathrm{HRVD}}$ conversion relationship has been derived using 98 events data for the magnitude range $4.8 \leq m_{\mathrm{b}, \mathrm{ISC}} \leq 6.2$, whereas the $m_{\mathrm{b}, \text { NEIC }}$ to $M_{\mathrm{w}, \mathrm{HRVD}}$ conversion relationship has been derived for the range $4.8 \leq m_{\mathrm{b}, \text { NEIC }} \leq 6.8$, based on 116 events data for the period 1978-2006.

On comparison, it is observed that the regression relationships derived in this paper for NE India 
region are almost similar to those given by Das et al (2011a) for NE India and adjoining region, but have slightly higher uncertainties in the regression parameters. Therefore, for homogenization of the catalogue, we prefer to use the OSR conversion relationships given by Das et al (2011a).

For deriving an empirical relationship between intensity $\left(I_{\max }\right)$ and moment magnitude $M_{\mathrm{w}, \text { NEIC }}$, data corresponding to MMI intensity VI and higher have only been used. In all, 126 intensity and $M_{\mathrm{w}, \text { NEIC }}$ data pairs for the whole globe are used in this relationship. The moment magnitude estimates yielded by the empirical relationship corresponding to intensity VI and above largely match with the range of values associated with different seismic zones in the seismic zoning map of India as per the code (IS-1893:2002) brought out by the Bureau of India Standards (BIS). The empirical relationship reported in this study can be used for conversion of intensity to $M_{\mathrm{w}}$ for historical earthquakes for which magnitude information is not available.

Declustering of the homogenized catalogue for the period 1897-2010 has been done using the method of Uhrhammer (1986) and there is a reduction of 905 events $(24.4 \%)$ during this process. Magnitude of completeness values have been obtained for the four catalogue periods namely, 18971963, 1964-1990, 1964-2000 and 1964-2010, using the EMR method. It is observed that the $M_{\mathrm{c}}$ value has decreased from 6.0 for 1897-1964 to 3.7 for 1964-2010, as expected due to the improvement in the detection threshold for this region from 1964 onwards. The improvement in the $M_{\mathrm{c}}$ value has important implications with regard to ' $b$ ' value determination and estimation of seismic hazard for the region.

From 1897-2010, several earthquakes with $M_{\mathrm{w}} \geq$ 7.0 have occurred in this region. A maximum time gap for the occurrence of a large earthquake $\left(M_{\mathrm{w}} \geq 7.0\right)$ is found to be 18 years (1970-1988) in the 1897-2010 catalogue. The last such event had occurred in this region in the year 1988. A phase of low seismic activity appears to have started from 1988 onwards and is continuing so far.

Keeping in view, the spatial variations in earthquake occurrence and prevalent tectonics, the study area has been subdivided into nine seismogenic zones. $M_{\mathrm{c}}$, ' $b$ ' and ' $a$ ' values have been estimated for each of these zones. The catalogue data for the period 1897-2010 reveals that zones I, VI and IX are devoid of earthquakes of magnitudes $\geq 7.0$. As zone IX is sandwiched between IV and VII zones in which large earthquakes have occurred, the probability of a large earthquake occurring in this region appears to be low relative to other zones. From these observations, a quiescence period is noticed in seismogenic zones, I and VI, for large magnitude earthquakes.

\section{Acknowledgements}

The authors are grateful to the reviewers for their critical reviews and constructive suggestions which helped to improve the technical content significantly. The suggestions by Dr Pawan Dewangan, Associate Editor, regarding the presentation of the manuscript are also thankfully acknowledged. The first author is thankful to MHRD, Govt. of India for research fellowship and AICTE, Govt. of India for award of National Doctoral Fellowship.

\section{References}

Angelier J and Baruah S 2009 Seismotectonics in Northeast India: A stress analysis of focal mechanism solutions of earthquake and it kinematic; Geophys. J. Int. 178 303-326.

Ambraseys N N 1990 Uniform magnitude re-evaluation of European earthquakes associated with strong-motion recordings; Earthquake Eng. Struct. Dyn. 19 1-20.

Bapat A, Kulkarni R C and Guha S K 1983 Catalogue of earthquakes in India and neighbourhood from historical period upto 1979; Indian Society of Earthquake Technology, Roorkee, India.

Carroll R J and Ruppert D 1996 The use and misuse of orthogonal regression in linear errors-in-variables models; Am. Stat. 50(1) 1-6.

Castellaro S and Bormann P 2007 Performance of different regression procedures on the magnitude conversion problem; Bull. Seismol. Soc. Am. 97 1167-1175.

Castellaro S, Mulargia F and Kagan YY 2006 Regression problems for magnitudes; Geophys. J. Int. 165 913-930.

Cavallini F and Rebez A 1996 Representing earthquake intensity magnitude relationship with a nonlinear function; Bull. Seismol. Soc. Am. 86 73-78.

Chandra U 1992 Seismotectonics of Himalaya; Curr. Sci. 62(1\&2) 40-71.

Das R, Wason H R and Sharma M L 2011a Homogenization of earthquake catalogue for Northeast India and adjoining region; Pure Appl. Geophys., doi: 10.1007/s00024-0110339-6.

Das R, Wason H R and Sharma M L 2011b Global regression relations for conversion of surface wave and body wave magnitudes to moment magnitude; Natural Hazards 59(2) 801-810, doi: 10.1007/s11069-011-9796-6.

Dutta T K 1964 Seismicity of Assam - zones of tectonic activity; Bull. Natl. Geophys. Res. Inst. 2 152-163.

Fuller W A 1987 Measurement Error Models; Wiley, New York.

Gardner J K and Knopoff L 1974 Is the sequence of earthquakes in southern California, with aftershocks removed, Poissonian? Bull. Seismol. Soc. Am. 64 1363-1367.

Gupta H K, Rajendran K and Singh H N 1986 Seismicity of Northeast India region: Part I: The database; J. Geol. Soc. India 28 345-365.

Gusev A A 1991 Intermagnitude relationships and asperity statistics; Pure Appl. Geophys. 136(N4) 515-527.

Gutdeutsch R, Kaiser D and Jentzsch G 2002 Estimation of earthquake magnitudes from epicentral intensities and other focal parameters in central and southern Europe; Geophys. J. Int. 151(N3) 824-834. 
IS: 1893-2002 Indian standard, criteria for earthquake resistant design of structures; Part I (5th edn), Bureau of Indian Standards, New Delhi.

Joshi G C and Sharma M L 2008 Uncertainties in the estimation of $M_{\max }$; J. Earth Syst. Sci. 117(S2) 671-682.

Kaverina A N, Lander A V and Prozorov A G 1996 Global creepex distribution and its relation to earthquake source geometry and tectonic origin; Geophys. J. Int. 125 249-265.

Kendall M G and Stuart A 1979 The advanced theory of statistics (Vol. 2, 4th edn), Griffin, London.

Madansky A 1959 The fitting of straight lines when both variables are subject to error; Am. Stat. Assoc. J. 54 173-205.

Panza G F, Prozorov A and Pazzi G 1993 Extension of global creepex definition $\left(M_{\mathrm{S}}-m_{\mathrm{b}}\right)$ to local studies $\left(M_{\mathrm{d}}-M_{\mathrm{L}}\right)$ : the case of the Italian region; Terra Nova. 5(N2) 150156.

Reasenberg P 1985 Second-order moment of central California seismicity, 1969-1982; J. Geophys. Res. 90 5479-5495.

Ristau J 2009 Comparison of magnitude estimates for New Zealand earthquakes: Moment magnitude, local magnitude, and teleseismic body-wave magnitude; Bull. Seismol. Soc. Am. 99 1841-1852.

Stromeyer D, Grünthal G and Wahlström R 2004 Chisquare regression for seismic strength parameter relation, and their uncertainties, with application to an $m_{\mathrm{w}}$-based earthquake catalogue for central, northern and northwestern Europe; J. Seismol. 8 143-153.

Thingbaijam K K, Nath S K, Yadav A, Raj A, Walling M Y and Mohanty W K 2008 Recent seismicity in Northeast India and its adjoining region; J. Seismol. 12 107-123.

Uhrhammer R A 1986 Characteristics of northern and central California seismicity; Earthquake Notes 57(1) 21 (abstract).

Utsu T 1965 A method for determining the value of $b$ in a formula $\log n=a-b M$ showing the magnitude-frequency relation for earthquakes (with English summary); Geophys. Bull. Hokkaido Uni. 13 99-103.

Wiemer S 2001 Software package to analyze seismicity: ZMAP; Seismol. Res. Lett. 72 373-382.

Woessner J and Wiemer S 2005 Assessing the quality of earthquake catalogues: Estimating the magnitude of completeness and its uncertainty; Bull. Seismol. Soc. Am. 95(2) 684-698. 